\title{
Two is More Than One: How to Combine Brain Stimulation Rehabilitative Training for Functional Recovery?
}

\author{
Satoko Koganemaru ${ }^{1,2 *}$, Hidenao Fukuyama ${ }^{2}$ and Tatsuya Mima ${ }^{2}$ \\ ${ }^{1}$ Brain Integrative Science, Kyoto University School of Medicine, Sakyo-ku, Kyoto, Japan, ${ }^{2}$ Human Brain Research Center, \\ Kyoto University School of Medicine, Sakyo-ku, Kyoto, Japan
}

OPEN ACCESS

Edited by:

Mikhail Lebedev,

Duke University, USA

Reviewed by:

Po-Yi Tsai,

Yang-Ming National University,

Taiwan

Anna-Katharine Brem,

University of Oxford, UK

Marco Sandrini,

University of Roehampton, UK

*Correspondence:

Satoko Koganemaru

kogane@kuhp.kyoto-u.ac.jp

Received: 13 November 2014 Accepted: 26 October 2015

Published: 10 November 2015

Citation:

Koganemaru S, Fukuyama H and Mima T (2015) Two is More Than

One: How to Combine Brain Stimulation and Rehabilitative Training

for Functional Recovery?

Front. Syst. Neurosci. 9:154.

doi: 10.3389/fnsys.2015.00154
A number of studies have shown that non-invasive brain stimulation has an additional effect in combination with rehabilitative therapy to enhance functional recovery than either therapy alone. The combination enhances use-dependent plasticity induced by repetitive training. The neurophysiological mechanism of the effects of this combination is based on associative plasticity. However, these effects were not reported in all cases. We propose a list of possible strategies to achieve an effective association between rehabilitative training with brain stimulation for plasticity: (1) control of temporal aspect between stimulation and task execution; (2) the use of a shaped task for the combination; (3) the appropriate stimulation of neuronal circuits where use-dependent plastic changes occur; and (4) phase synchronization between rhythmically patterned brain stimulation and task-related patterned activities of neurons. To better utilize brain stimulation in neuro-rehabilitation, it is important to develop more effective techniques to combine them.

Keywords: use-dependent plasticity, associative plasticity, neuro-rehabilitation, transcranial magnetic stimulation (TMS), transcranial direct current stimulation (tDCS)

\section{USE-DEPENDENT PLASTICITY ENHANCED BY THE COMBINATION OF REHABILITATIVE TRAINING AND BRAIN STIMULATION}

Repetitive training is one of the fundamental strategies in neuro-rehabilitation regardless of what type of damage has occurred in the central or peripheral nervous system. Task-specific training induces task-specific neuronal changes lasting for a long period i.e., use-dependent plasticity that can lead to functional recovery (Butefisch et al., 1995; Nudo and Milliken, 1996; Nudo et al., 1996a,b; Hummelsheim, 1999; Masiero and Carraro, 2008; Richards et al., 2008; Dimyan and Cohen, 2011). Use-dependent plasticity induced by motor training has been demonstrated within the human primary motor cortex (M1). The long-term potentiation (LTP)-like changes in specific cortcospinal motoneurons were induced for the trained task after repetitive simple finger movements (Classen et al., 1998; Butefisch et al., 2000; Rossini and Pauri, 2000).

In recent decades, a number of studies have shown that non-invasive brain stimulation such as repetitive transcranial magnetic stimulation (rTMS) or transcranial direct current stimulation (tDCS) has an add-on effect in combination with rehabilitative therapy 
(Platz and Rothwell, 2010; Edwardson et al., 2013; Sandrini and Cohen, 2013; Floel, 2014). Furthermore, this combination may better enhance functional recovery in post-stroke patients, as compared with rehabilitation training alone, which may not sufficiently induce functional recovery (Khedr et al., 2005, 2010; Kim et al., 2006, 2010; Takeuchi et al., 2008; Chang et al., 2010, 2012; Emara et al., 2010; Koganemaru et al., 2010; Conforto et al., 2012; Meehan et al., 2011; Nair et al., 2011; Stagg and Nitsche, 2011; Wang et al., 2012; Hsu et al., 2013), especially in the chronic phase when it is difficult to produce plastic changes (Nakayama et al., 1994; Verheyden et al., 2008). A single intervention of brain stimulation alone without rehabilitative therapy seems to have limited effects on patients with mild motor symptoms (Hummel and Cohen, 2005; Koganemaru et al., 2010) and insufficient sustainability of effects (Takeuchi et al., 2005; Kim et al., 2009). Whereas the combination may enhance use-dependent plasticity induced by repetitive training.

\section{ASSOCIATIVE PLASTICITY TO PRODUCE THE COMBINATION EFFECTS}

Although the exact neurophysiological mechanism of this combination effect is not known yet, it may be based on Hebbian associative plasticity (Hebb, 1949). For example, a post-synaptic neuron (A) receives low-frequency weak inputs from one presynaptic neuron (B) (the inputs themselves cannot induce LTP in a synaptic connection). Simultaneously, neuron (A) receives high-frequency weak inputs (the inputs themselves can induce LTP) from another pre-synaptic neuron (C). According to the Hebbian rule, LTP is also induced in the weak synaptic connection between neurons (A) and (B) as well as between neurons (A) and (C). A similar mechanism would work in the case of the combination of training with brain stimulation. Training alone may only produce a weak activation of neuronal circuits, which do not lead to long term changes. On the other hand, brain stimulation can induce LTP-like changes for synaptic strength in stimulated areas (Pascual-Leone et al., 1994; Hallett, 2000; Fritsch et al., 2010; Dayan et al., 2013; Karabanov et al., 2015). Therefore, simultaneous training with brain stimulation would enable weak synaptic connections to induce associative LTP-like effects through the Hebbian rule.

However, a recent study reported no additional effects of theta-burst stimulation (TBS) in combination with standardized rehabilitative therapy in chronic stroke patients. That might be possibly due to a failure to induce associative plasticity. Neuronal activities enhanced by TBS may not have been associated with task-specific neuronal activities produced by the rehabilitative therapy (Talelli et al., 2012).

We can speculate and make a list of possible factors that may have weakened the therapeutic effects of combined rehabilitation and brain stimulation:

1. Diversities in diseases, particularly the locations of lesions

- The effects of facilitatory rTMS over M1 depended on lesion location in post-stroke hemiparetic patients. The deterioration of finger function was seen in the patients with cortical lesions, whereas improvement in finger function was seen in patients with subcortical lesions (Ameli et al., 2009).

2. Small sample size

- The responses to brain stimulation show a large variability even if patients are similar in lesion location, severity of paresis and time after stroke onset in patients. Genetic factors are responsible for individual susceptibility to rTMS-induced plasticity (Cheeran et al., 2008).

3. Insufficient intensity and/or too short duration of the intervention

- Patients with severe paresis show reduced or no motor evoked potentials (MEP) with TMS (Pennisi et al., 1999; Hendricks et al., 2002). If the intensity of brain stimulation is determined by the excitability of the healthy hemisphere, it may be too weak to induce plasticity in the affected hemisphere. Unless brain stimulation is repeated daily for days to weeks, its effects might not be sustainable (Khedr et al., 2009; Emara et al., 2010; Bolognini et al., 2011; Conforto et al., 2012; Edwardson et al., 2013).

4. Inappropriate affinity between rehabilitation task and brain stimulation modality

- This will be discussed in detail in the following section.

Future clinical studies should give careful consideration to these factors. We have considered how effectively we can induce associative plasticity through the combination of training and brain stimulation.

\section{EFFECTIVE METHODS OF COMBINING REHABILITATIVE TRAINING AND BRAIN STIMULATION}

\section{Control of the Temporal Aspect Between Stimulation and Task Execution}

First, we should control the temporal aspect between stimulation and task execution. Spike timing-dependent associative plasticity has been proven in both animals (Hess and Donoghue, 1996; Hess et al., 1996; Egger et al., 1999) and humans (Stefan et al., 2000, 2002; Ueki et al., 2006; Koganemaru et al., 2009). Associative LTP occurs when a post-synaptic neuron fires less than 10-20 ms after a pre-synaptic neuron. Recently, we have demonstrated that associative plasticity is induced within human M1. The repetitive pairing of TMS and paired bihemispheric stimulation (PBS) applied at a time interval of $15 \mathrm{~ms}$, produced an associative LTP-like effect within the targeted M1 and facilitated fine finger movements (Koganemaru et al., 2009). Furthermore, associative use-dependent plasticity has been demonstrated within human M1. Thabit et al. (2010) showed that associative LTP-like changes were induced by the repetitive paring of a unidirectional finger movement and a single TMS pulse over the contralateral M1 with a specific interval in healthy subjects. It resulted in a faster reaction in the trained direction. By decrease or increase of the interval, LTP-like effects can disappear or be reversed. Buetefisch et al. (2011) showed that the extensor-specific M1 reorganization was induced by robot-assisted training of paretic wrist extension combined with TMS over the ipsilesional M1 in a strict temporal relationship 
in chronic post-stroke patients. Particularly, a decrease of motor threshold and a shift of motor mapping for the extensor carpi ulnaris muscles, not the biceps muscles, were demonstrated in the combination therapy with TMS over the ipsilesional M1. The training alone and the simulation protocol with TMS over the contralesional M1 did not show those changes. The results suggest that temporal associative plasticity is induced specifically for the extensor-related activity in the ipsilesional M1. If we can associate brain stimulation and task execution with proper timing, a task-specific associative plasticity may be induced. There is a large variability in movement onset of the paretic limbs after neurological insults. The central motor conduction time is prolonged in stroke and other neurodegenerative diseases due to lesions in the corticospinal tract (Kaviraja and Robert, 2013). It is influenced by time after disease onset or disease progression. On the other hand, electromyogram (EMG) onsets are often variable since it is difficult to increase firing rate in central nervous diseases (Barnes, 1980). Therefore, when we do simultaneous TMS with training, we may as well be careful for both the timing for TMS and task execution.

\section{Use of a Shaped Task for the Combination}

An effective rehabilitative approach should consist of various types of training pertaining to body movements in enriched environments that encourage patterns and combinations of movement for improving recovery. Different types of taskspecific training help their effects transfer into actual activities of daily life in patients (Teasell et al., 2005). However, a specific task or tasks for specific movements are better combined with brain stimulation. If a task consists of various gross and precise movements, it may evoke conflicting neuronal activities such as inhibition and activation. Then, it may reduce the effect of brain stimulation. In recent animal studies, it was shown that training general gross movements inhibited recovery of skilled movements (Garcia-Alias et al., 2009). Neural competition for newly available neural resources may occur when multiple tasks are trained (Reinkensmeyer and Boninger, 2012). In clinical studies, task-specificity of training is more important than the intensity of training (Page, 2003; Bayona et al., 2005). The repetition of task-specific training produced long-lasting cortical reorganization and use-dependent plasticity specific to the areas that were activated during the trained movements in healthy subjects (Classen et al., 1998; Butefisch et al., 2000). In poststroke patients, shaped task-specific training resulted in a better recovery of their paretic upper-limb function as compared with general training (Butefisch et al., 1995; Woldag et al., 2010).

Recently, we have investigated the effect of repetitive motor tasks in the paretic upper-limb combined with brain stimulation in post-stroke patients (Koganemaru et al., 2010). Patients with chronic stroke with moderate-to-severe hemiparesis often suffer from motor deficits associated with flexor hypertonia. A possible therapeutic strategy is to selectively induce usedependent plasticity in the extensors to counteract the flexor hypertonia. However, the beneficial effects of training in chronic-phase patients are relatively limited due to resistance to induction of use-dependent plasticity in the chronic phase (Nakayama et al., 1994; Verheyden et al., 2008). When 5 Hz rTMS over the ipsilesional M1 was combined with extensor training assisted by electrical neuromuscular stimulation, the combined intervention resulted in an improvement of extensor movement with a reduction of flexor hypertonia, whereas neither of the single interventions alone demonstrated any improvements. The extensor-specific change in M1 was likely attributable to a functional recovery of the paretic upper limb (Koganemaru et al., 2010). Our study is an exemplary case showing the relevance of task selection combined with brain stimulation to enhance usedependent plasticity for functional recovery.

\section{The Stimulation of Neuronal Circuits Where Use-Dependent Plastic Changes Occur}

Stimulation should be given to neuronal circuits and brain areas where use-dependent plastic changes occur. Because usedependent plasticity is task-specific, changed circuits and areas depend on what type of task was trained. For repetitive simple motor tasks, use-dependent plastic changes have been reported within M1 (Classen et al., 1998; Butefisch et al., 2000; Rossini and Pauri, 2000). However, it is unknown whether it occurs within M1 alone or in combination with the multi-regional functional reorganization of the motor-related brain network. If it occurs in a multi-regional brain network, other non-M1 regions would be the possible targets of stimulation.

Recently, we used neuroimaging to investigate whether use-dependent changes occurred in a multiregional brain network in chronic post-stroke patients (Koganemaru et al., 2015). In process of post-stroke recovery with rehabilitative

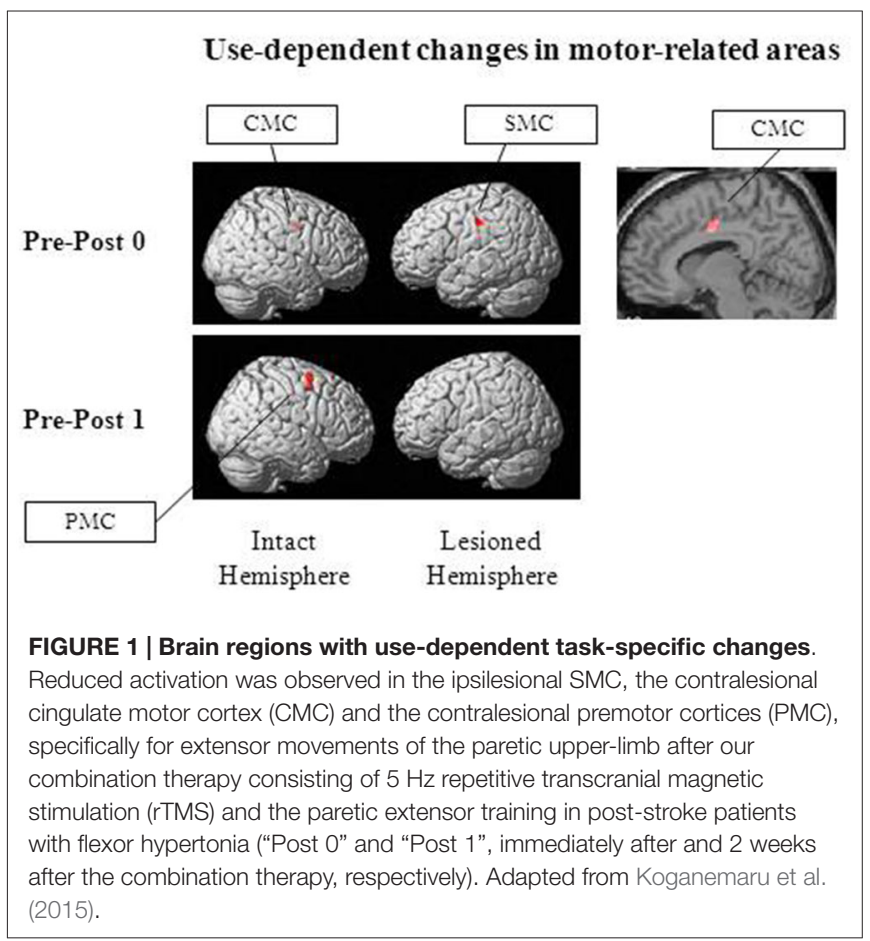


training, neuroimaging studies demonstrated that multiregional brain reorganization occurred in several motor-related regions, including bilateral $\mathrm{M} 1$, premotor cortices (PMC), cingulate motor cortex (CMC), basal ganglia, and cerebellum (Nelles et al., 2001; Carey et al., 2002; Johansen-Berg et al., 2002a; Jang et al., 2003, 2005; Ward et al., 2003a, 2004; Luft et al., 2004; Ward and Cohen, 2004). The over-activity of non-M1 regions such as bilateral PMC in the acute stage was progressively decreased with an improvement in motor performance of the hemiparetic limbs (Calautti et al., 2001; Small et al., 2002; Ward et al., 2003a). In the chronic stage, the magnitude of brain activity in the non-M1 regions was negatively correlated with clinical outcome (Ward et al., 2003a,b) and positively correlated with the extent of damage in the corticospinal system (Ward et al., 2006). The findings suggest that the compensatory mechanism of these regions may be due to insufficient motor recovery (Feydy et al., 2002; Ward et al., 2003b). Those patients with larger brain damage and poorer clinical recovery may rely on activity in secondary motor areas to drive residual hand function (Johansen-Berg et al., 2002b). If a combination therapy of a task-specific training and brain stimulation could restore the ipsilesional M1 function by use-dependent plasticity, compensatory drive from secondary motor areas would be changed in post-stroke patients.

As previously described, we have developed a new combination therapy consisting of $5 \mathrm{~Hz}$ rTMS and an electrical neuromuscular stimulation assisted extensor training of the paretic upper-limb for stroke patients with flexor hypertonia. The extensor-specific plastic change in M1 was associated with beneficial functional effects (Koganemaru et al., 2010). We investigated whether extensor-specific multiregional brain reorganization occurred after our combination therapy by using functional magnetic resonance imaging (fMRI). The patients were scanned while performing upper-limb extensor movements. Untrained flexor movements were used as a control condition. Assessments were performed before, immediately after, and 2 weeks after the hybrid rehabilitation protocol. Analysis of the imaging data showed a significant reduction of brain activity in the ipsilesional SMC and the contralesional CMC immediately after (Post 0 ) and in the contralesional PMC 2 weeks after the intervention (Post 1; Figure 1). It suggests that the effects of the hybrid-rehabilitation appeared to differ temporally in each brain area. The process of motor learning consists of a fast learning stage and a slow learning stage. Specific neural representations are known in each stage (Karni et al., 1998; Kantak et al., 2012). The changes in activity in the ipsilesional SMC and the contralesional CMC may have shown combined effects of the fast learning stage, whereas the activity change in the contralesional PMC may have been involved in a consolidative process of the slow learning stage. Furthermore, the changes were associated with functional improvements of the paretic hands. They were not shown for the control condition (Koganemaru et al., 2015). Use-dependent plasticity induced by repetitive training may be related to the task-specific multiregional brain reorganization. Thus, we expect that possible future targets for brain stimulation could include secondary motor areas. Artificial control of compensatory drive from secondary motor areas in accordance with the recovery process may be the next target for a combination therapy.
Phase synchronization between (a) and (b)

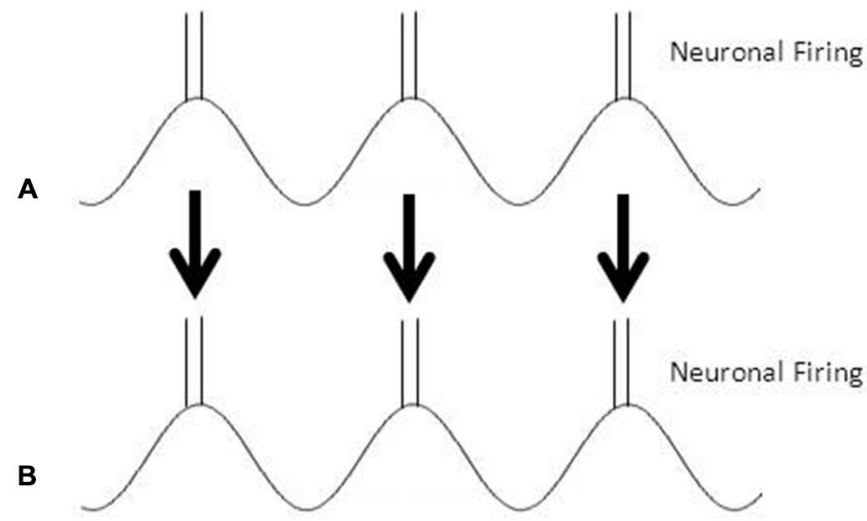

duction of

spike timing-dependent plasticity
No phase synchronization between (a) and (c)

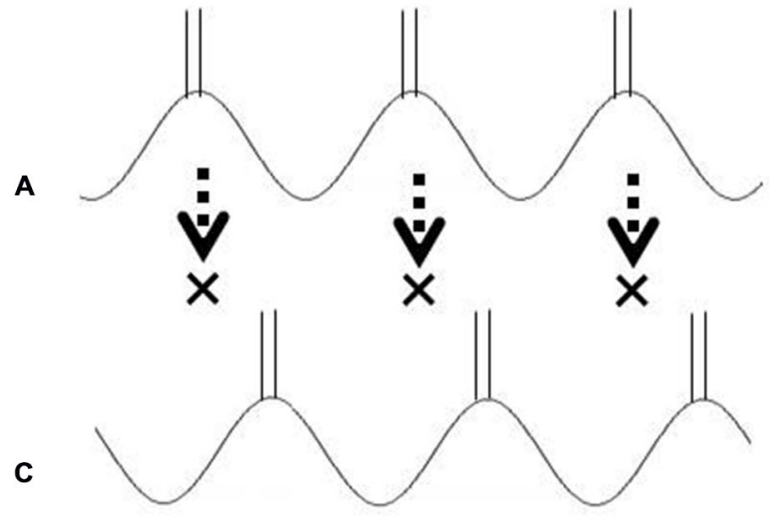

FIGURE 2 | Phase synchronization and temporal associative plasticity. Phase synchronization enables neurons in two different regions (A) and (B) to fire at the same timing, leading to an induction of spike-timing dependent plasticity between these regions. No synchronization of phases between the two regions ( $\mathbf{A}$ ) and (C) with different timing of neuronal firing does not induce any plasticity. 


\section{Phase Synchronization Between Rhythmically Patterned Brain Stimulation and Task-Related Patterned Activities of Neurons}

In line with the theory of associative plasticity, we may be able to utilize the synchronization of phases between rhythmically patterned brain stimulation and task-related rhythmical activities of neurons. The phase synchronization of pre- and post-synaptic oscillations (wave-like neuronal signals) enabled researchers to correlate the timing of pre- and post-synaptic action potentials, resulting in the induction of temporal associative plasticity (Fell and Axmacher, 2011). Oscillatory non-invasive brain stimulation such as transcranial alternative current stimulation (tACS) and oscillatory tDCS (otDCS) has been reported to modulate oscillatory brain activity (Herrmann et al., 2013). Both tACS and otDCS use a sinusoidal form of electrical currents; however, tACS has no DC offset (net current $=0$ ) and otDCS has a DC offset (net current $=$ DC offset). In otDCS, the alternating current is superimposed onto a direct current. These protocols of stimulation may enhance neuronal circuits associated with intrinsic rhythmicity, leading to the enhancement of cognitive function (Marshall et al., 2006; Castro-Alamancos et al., 2007; Kanai et al., 2008, 2010; Kirov et al., 2009; Zaehle et al., 2010). In a recent study, phase-synchronized tACS suppressed Parkinson tremor by adjusting the phase to an abnormal cycle of the movements (Brittain et al., 2013). Rhythmical movements are produced with neuronal rhythmicity, a periodical repeat of excitation and inhibition. If oscillatory brain stimulation is synchronized with them at an appropriate phase, temporal associative plasticity may be induced (Figure 2).

One of the most familiar rhythmical movements in our daily life is locomotion, which requires the repeated patterned activation of specific neurons and muscles. Recently, in a preliminary experiment, we found that otDCS simulating gait rhythm induced gait-specific plasticity in healthy subjects (Koganemaru et al., 2014). Oscillatory patterned brain

\section{REFERENCES}

Ameli, M., Grefkes, C., Kemper, F., Riegg, F. P., Rehme, A. K., Karbe, H., et al. (2009). Differential effects of high-frequency repetitive transcranial magnetic stimulation over ipsilesional primary motor cortex in cortical and subcortical middle cerebral artery stroke. Ann. Neurol. 66, 298-309. doi: 10.1002/ana.21725

Barnes, W. S. (1980). The relationship of motor-unit activation to isokinetic muscular contraction at different contractile velocities. Phys. Ther. 60, $1152-1158$.

Bayona, N. A., Bitensky, J., Salter, K., and Teasell, R. (2005). The role of taskspecific training in rehabilitation therapies. Top Stroke Rehabil. 12, 58-65. doi: 10.1310/bqm5-6ygb-mvj5-wvcr

Bolognini, N., Vallar, G., Casati, C., Latif, L. A., El-Nazer, R., Williams, J., et al. (2011). Neurophysiological and behavioral effects of tDCS combined with constraint-induced movement therapy in poststroke patients. Neurorehabil. Neural Repair 25, 819-829. doi: 10.1177/1545968311411056

Brittain, J. S., Probert-Smith, P., Aziz, T. Z., and Brown, P. (2013). Tremor suppression by rhythmic transcranial current stimulation. Curr. Biol. 23, 436-440. doi: 10.1016/j.cub.2013.01.068

Buetefisch, C., Heger, R., Schicks, W., Seitz, R., and Netz, J. (2011). Hebbiantype stimulation during robot-assisted training in patients with stroke. Neurorehabil. Neural Repair 25, 645-655. doi: 10.1177/1545968311402507 stimulation could be a new and powerful approach for the association of neuronal activities involved with training.

\section{CONCLUSION}

We have proposed the possible strategies for combination therapy of stimulation and rehabilitative trainings: (1) the control of temporal aspect between stimulation and task execution; (2) the use of a shaped task for the combination; (3) the appropriate stimulation of neuronal circuits where usedependent plastic changes occur; and (4) phase synchronization between rhythmically patterned brain stimulation and taskrelated patterned activities of neurons. Associative brain plasticity induced by the combination therapy can bring functional improvements in patients.

There are still many diseases that are resistant to neurorehabilitative approaches. To better utilize brain stimulation in neuro-rehabilitation, we must explore more effective techniques for combining brain stimulation and rehabilitative training. An efficient association between brain stimulation and rehabilitative training could improve brain plasticity and promote functional recovery of patients.

\section{ACKNOWLEDGMENTS}

This study was partly supported by Grant-in-Aid for JSPS Fellows (25-5251), by Grant-in-Aid for Young Scientists (B) (26870321) from the Japan Society for the Promotion of Science, by the research grant (2015) from the Nakatomi Foundation (to SK), by Grant-in-Aid for Scientific Research (B) 15H03044, Grant-in-Aid for Scientific Research on Innovative Areas $(15 \mathrm{H} 05880,15 \mathrm{H} 05871)$ from the Japan Society for the Promotion of Science, STEP2 (15ek0109078h0001) from Japan Agency for Medical Research and development, AMED and the research grant (2015) from the Brain Science Foundation (to TM).

Butefisch, C., Hummelsheim, H., Denzler, P., and Mauritz, K. H. (1995). Repetitive training of isolated movements improves the outcome of motor rehabilitation of the centrally paretic hand. J. Neurol. Sci. 130, 59-68. doi: 10.1016/0022$510 x(95) 00003-\mathrm{k}$

Butefisch, C. M., Davis, B. C., Wise, S. P., Sawaki, L., Kopylev, L., Classen, J., et al. (2000). Mechanisms of use-dependent plasticity in the human motor cortex. Proc. Natl. Acad. Sci. U S A 97, 3661-3665. doi: 10.1073/pnas.97. 7.3661

Calautti, C., Leroy, F., Guincestre, J. Y., and Baron, J. C. (2001). Dynamics of motor network overactivation after striatocapsular stroke: a longitudinal PET study using a fixed-performance paradigm. Stroke 32, 2534-2542. doi: 10. 1161/hs1101.097401

Carey, J. R., Kimberley, T. J., Lewis, S. M., Auerbach, E. J., Dorsey, L., Rundquist, P., et al. (2002). Analysis of fMRI and finger tracking training in subjects with chronic stroke. Brain 125, 773-788. doi: 10.1093/brain/awf091

Castro-Alamancos, M. A., Rigas, P., and Tawara-Hirata, Y. (2007). Resonance (approximately $10 \mathrm{~Hz}$ ) of excitatory networks in motor cortex: effects of voltage-dependent ion channel blockers. J. Physiol. 578, 173-191. doi: 10. 1113/jphysiol.2006.119016

Chang, W. H., Kim, Y. H., Bang, O. Y., Kim, S. T., Park, Y. H., and Lee, P. K. (2010) Long-term effects of rTMS on motor recovery in patients after subacute stroke. J. Rehabil. Med. 42, 758-764. doi: 10.2340/16501977-0590 
Chang, W. H., Kim, Y. H., Yoo, W. K., Goo, K. H., Park, C. H., Kim, S. T., et al. (2012). rTMS with motor training modulates cortico-basal gangliathalamocortical circuits in stroke patients. Restor. Neurol. Neurosci. 30, 179-189. doi: 10.3233/RNN-2012-110162

Cheeran, B., Talelli, P., Mori, F., Koch, G., Suppa, A., Edwards, M., et al. (2008). A common polymorphism in the brain-derived neurotrophic factor gene (BDNF) modulates human cortical plasticity and the response to rTMS. J. Physiol. Lond. 586, 5717-5725. doi: 10.1113/jphysiol.2008

Classen, J., Liepert, J., Wise, S. P., Hallett, M., and Cohen, L. G. (1998). Rapid plasticity of human cortical movement representation induced by practice. J. Neurophysiol. 79, 1117-1123.

Conforto, A. B., Anjos, S. M., Saposnik, G., Mello, E. A., Nagaya, E. M., Santos, W., et al. (2012). Transcranial magnetic stimulation in mild to severe hemiparesis early after stroke: a proof of principle and novel approach to improve motor function. J. Neurol. 259, 1399-1405. doi: 10.1007/s00415-0116364-7

Dayan, E., Censor, N., Buch, E. R., Sandrini, M., and Cohen, L. G. (2013). Noninvasive brain stimulation: from physiology to network dynamics and back. Nat. Neurosci. 16, 838-844. doi: 10.1038/nn.3422

Dimyan, M. A., and Cohen, L. G. (2011). Neuroplasticity in the context of motor rehabilitation after stroke. Nat. Rev. Neurol. 7, 76-85. doi: 10.1038/nrneurol. 2010.200

Edwardson, M. A., Lucas, T. H., Carey, J. R., and Fetz, E. E. (2013). New modalities of brain stimulation for stroke rehabilitation. Exp. Brain Res. 224, 335-358. doi: 10.1007/s00221-012-3315-1

Egger, V., Feldmeyer, D., and Sakmann, B. (1999). Coincidence detection and changes of synaptic efficacy in spiny stellate neurons in rat barrel cortex. Nat. Neurosci. 2, 1098-1105.

Emara, T. H., Moustafa, R. R., Elnahas, N. M., Elganzoury, A. M., Abdo, T. A., Mohamed, S. A., et al. (2010). Repetitive transcranial magnetic stimulation at $1 \mathrm{~Hz}$ and $5 \mathrm{~Hz}$ produces sustained improvement in motor function and disability after ischaemic stroke. Eur. J. Neurol. 17, 1203-1209. doi: 10.1111/j.1468-1331. 2010.03000.x

Fell, J., and Axmacher, N. (2011). The role of phase synchronization in memory processes. Nat. Rev. Neurosci. 12, 105-118. doi: 10.1038/nrn2979

Feydy, A., Carlier, R., Roby-Brami, A., Bussel, B., Cazalis, F., Pierot, L., et al. (2002). Longitudinal study of motor recovery after stroke: recruitment and focusing of brain activation. Stroke 33, 1610-1617. doi: 10.1161/01.str.0000017100. 68294.52

Floel, A. (2014). tDCS-enhanced motor and cognitive function in neurological diseases. Neuroimage 85, 934-947. doi: 10.1016/j.neuroimage.2013.05.098

Fritsch, B., Reis, J., Martinowich, K., Schambra, H. M., Ji, Y., Cohen, L. G., et al. (2010). Direct current stimulation promotes BDNF-dependent synaptic plasticity: potential implications for motor learning. Neuron 66, 198-204. doi: 10.1016/j.neuron.2010.03.035

Garcia-Alias, G., Barkhuysen, S., Buckle, M., and Fawcett, J. W. (2009). Chondroitinase $\mathrm{ABC}$ treatment opens a window of opportunity for taskspecific rehabilitation. Nat. Neurosci. 12, 1145-1151. doi: 10.1038/nn.2377

Hallett, M. (2000). Transcranial magnetic stimulation and the human brain. Nature 406, 147-150. doi: 10.1038/35018000

Hebb, D. O. (1949). The Organization of Behavior: A Neuropsychological Theory. New York, NY: Wiley.

Hendricks, H. T., Van Limbeek, J., Geurts, A. C., and Zwarts, M. J. (2002). Motor recovery after stroke: a systematic review of the literature. Arch. Phys. Med. Rehabil. 83, 1629-1637. doi: 10.1053/apmr.2002.35473

Herrmann, C. S., Rach, S., Neuling, T., and Struber, D. (2013). Transcranial alternating current stimulation: a review of the underlying mechanisms and modulation of cognitive processes. Front. Hum. Neurosci. 7:279. doi: 10. 3389/fnhum.2013.00279

Hess, G., Aizenman, C. D., and Donoghue, J. P. (1996). Conditions for the induction of long-term potentiation in layer II/III horizontal connections of the rat motor cortex. J. Neurophysiol. 75, 1765-1778.

Hess, G., and Donoghue, J. P. (1996). Long-term potentiation and long-term depression of horizontal connections in rat motor cortex. Acta. Neurobiol. Exp. (Wars) 56, 397-405.

Hsu, Y. F., Huang, Y. Z., Lin, Y. Y., Tang, C. W., Liao, K. K., Lee, P. L., et al. (2013). Intermittent theta burst stimulation over ipsilesional primary motor cortex of subacute ischemic stroke patients: a pilot study. Brain Stimul. 6, 166-174. doi: 10.1016/j.brs.2012.04.007
Hummel, F. C., and Cohen, L. G. (2005). Drivers of brain plasticity. Curr. Opin. Neurol. 18, 667-674. doi: 10.1097/01.wco.0000189876.37475.42

Hummelsheim, H. (1999). Rationales for improving motor function. Curr. Opin. Neurol. 12, 697-701. doi: 10.1097/00019052-199912000-00007

Jang, S. H., Kim, Y. H., Cho, S. H., Chang, Y., Lee, Z. I., and Ha, J. S. (2003). Cortical reorganization associated with motor recovery in hemiparetic stroke patients. Neuroreport 14, 1305-1310. doi: 10.1097/01.wnr.0000078700. 79393.09

Jang, S. H., You, S. H., Hallett, M., Cho, Y. W., Park, C. M., Cho, S. H., et al. (2005). Cortical reorganization and associated functional motor recovery after virtual reality in patients with chronic stroke: an experimenter-blind preliminary study. Arch. Phys. Med. Rehabil. 86, 2218-2223. doi: 10.1016/j.apmr.2005. 04.015

Johansen-Berg, H., Dawes, H., Guy, C., Smith, S. M., Wade, D. T., and Matthews, P. M. (2002a). Correlation between motor improvements and altered fMRI activity after rehabilitative therapy. Brain 125, 2731-2742. doi: 10. 1093/brain/awf282

Johansen-Berg, H., Rushworth, M. F., Bogdanovic, M. D., Kischka, U., Wimalaratna, S., and Matthews, P. M. (2002b). The role of ipsilateral premotor cortex in hand movement after stroke. Proc. Natl. Acad. Sci. U S A 99, 14518-14523. doi: 10.1073/pnas.222536799

Kanai, R., Chaieb, L., Antal, A., Walsh, V., and Paulus, W. (2008). Frequencydependent electrical stimulation of the visual cortex. Curr. Biol. 18, 1839-1843. doi: 10.1016/j.cub.2008.10.027

Kanai, R., Paulus, W., and Walsh, V. (2010). Transcranial alternating current stimulation (tACS) modulates cortical excitability as assessed by TMS-induced phosphene thresholds. Clin. Neurophysiol. 121, 1551-1554. doi: 10.1016/j. clinph.2010.03.022

Kantak, S. S., Stinear, J. W., Buch, E. R., and Cohen, L. G. (2012). Rewiring the brain: potential role of the premotor cortex in motor control, learning and recovery of function following brain injury. Neurorehabil. Neural Repair 26, 282-292. doi: 10.1177/1545968311420845

Karabanov, A., Ziemann, U., Hamada, M., George, M. S., Quartarone, A., Classen, J., et al. (2015). Consensus paper: probing homeostatic plasticity of human cortex with non-invasive transcranial brain stimulation. Brain Stimul. 8, 442-454. doi: 10.1016/j.brs.2015.01.404

Karni, A., Meyer, G., Rey-Hipolito, C., Jezzard, P., Adams, M. M., Turner, R., et al. (1998). The acquisition of skilled motor performance: fast and slow experiencedriven changes in primary motor cortex. Proc. Natl. Acad. Sci. U S A 95, 861-868. doi: 10.1073/pnas.95.3.861

Kaviraja, U., and Robert, C. (2013). "Central motor conduction time," in Handbook of Clinical Neurology, Brain Stimulation, eds A. M. Lozano and M. Hallett (Amsterdam: Elsevier B.V.), 375-386. doi: 10.1007/978-3-540-296782_891

Khedr, E. M., Abdel-Fadeil, M. R., Farghali, A., and Qaid, M. (2009). Role of 1 and $3 \mathrm{~Hz}$ repetitive transcranial magnetic stimulation on motor function recovery after acute ischaemic stroke. Eur. J. Neurol. 16, 1323-1330. doi: 10.1111/j.14681331.2009.02746.x

Khedr, E. M., Ahmed, M. A., Fathy, N., and Rothwell, J. C. (2005). Therapeutic trial of repetitive transcranial magnetic stimulation after acute ischemic stroke. Neurology 65, 466-468. doi: 10.1212/01.wnl.0000173067.84247.36

Khedr, E. M., Etraby, A. E., Hemeda, M., Nasef, A. M., and Razek, A. A. (2010) Long-term effect of repetitive transcranial magnetic stimulation on motor function recovery after acute ischemic stroke. Acta. Neurol. Scand. 121, 30-37. doi: 10.1111/j.1600-0404.2009.01195.x

Kim, D. Y., Lim, J. Y., Kang, E. K., You, D. S., Oh, M. K., Oh, B. M., et al. (2010). Effect of transcranial direct current stimulation on motor recovery in patients with subacute stroke. Am. J. Phys. Med. Rehabil. 89, 879-886. doi: 10.1097/phm. 0b013e3181f70aa7

Kim, D. Y., Ohn, S. H., Yang, E. J., Park, C. I., and Jung, K. J. (2009). Enhancing motor performance by anodal transcranial direct current stimulation in subacute stroke patients. Am. J. Phys. Med. Rehabil. 88, 829-836. doi: 10. 1097/phm.0b013e3181b811e3

Kim, Y. H., You, S. H., Ko, M. H., Park, J. W., Lee, K. H., Jang, S. H., et al. (2006). Repetitive transcranial magnetic stimulation-induced corticomotor excitability and associated motor skill acquisition in chronic stroke. Stroke 37, 1471-1476. doi: 10.1161/01.str.000221233.55497.51

Kirov, R., Weiss, C., Siebner, H. R., Born, J., and Marshall, L. (2009). Slow oscillation electrical brain stimulation during waking promotes EEG theta 
activity and memory encoding. Proc. Natl. Acad. Sci. U S A 106, 15460-15465. doi: 10.1073/pnas.0904438106

Koganemaru, S., Mikami, Y., Fukuyama, H., and Mima, T. (2014). Slow oscillatory stimulation simulating gait rhythm induces LTP-like effects on corticospinal excitability in foot. Clin. Neurophysiol. 125, Suppl 1, Abstracts of the 30th International Congress of Clinical Neurophysiology (ICCN) of the IFCN, March 20-23 2014, Berlin, Germany, S223.

Koganemaru, S., Mima, T., Nakatsuka, M., Ueki, Y., Fukuyama, H., and Domen, K. (2009). Human motor associative plasticity induced by paired bihemispheric stimulation. J. Physiol. 587, 4629-4644. doi: 10.1113/jphysiol.2009.174342

Koganemaru, S., Mima, T., Thabit, M. N., Ikkaku, T., Shimada, K., Kanematsu, M., et al. (2010). Recovery of upper-limb function due to enhanced usedependent plasticity in chronic stroke patients. Brain 133, 3373-3384. doi: 10. 1093/brain/awq193

Koganemaru, S., Sawamoto, N., Aso, T., Sagara, A., Ikkaku, T., Shimada, K., et al. (2015). Task-specific brain reorganization in motor recovery induced by a hybrid-rehabilitation combining training with brain stimulation after stroke. Neurosci. Res. 92, 29-38. doi: 10.1016/j.neures.2014.10.004

Luft, A. R., Mccombe-Waller, S., Whitall, J., Macko, R., Sorkin, J. D., Schulz, J. B., et al. (2004). Repetitive bilateral arm training and motor cortex activation in chronic stroke: A randomized controlled trial. JAMA 292, 1853-1861. doi: 10. 1001/jama.292.20.2470-b

Marshall, L., Helgadottir, H., Molle, M., and Born, J. (2006). Boosting slow oscillations during sleep potentiates memory. Nature 444, 610-613. doi: $10.1038 /$ nature 05278

Masiero, S., and Carraro, E. (2008). Upper limb movements and cerebral plasticity in post-stroke rehabilitation. Aging Clin. Exp. Res. 20, 103-108. doi: 10. 1007/bf03324755

Meehan, S. K., Dao, E., Linsdell, M. A., and Boyd, L. A. (2011). Continuous theta burst stimulation over the contralesional sensory and motor cortex enhances motor learning post-stroke. Neurosci. Lett. 500, 26-30. doi: 10.1016/j.neulet. 2011.05.237

Nair, D. G., Renga, V., Lindenberg, R., Zhu, L., and Schlaug, G. (2011). Optimizing recovery potential through simultaneous occupational therapy and noninvasive brain-stimulation using tDCS. Restor. Neurol. Neurosci. 29, 411-420. doi: 10.3233/RNN-2011-0612

Nakayama, H., Jorgensen, H. S., Raaschou, H. O., and Olsen, T. S. (1994). Recovery of upper extremity function in stroke patients: the Copenhagen Stroke Study. Arch. Phys. Med. Rehabil. 75, 394-398.

Nelles, G., Jentzen, W., Jueptner, M., Müller, S., and Diener, H. C. (2001). Arm training induced brain plasticity in stroke studied with serial positron emission tomography. NeuroImage 13, 1146-1154. doi: 10.1006/nimg.2001.0757

Nudo, R. J., and Milliken, G. W. (1996). Reorganization of movement representations in primary motor cortex following focal ischemic infarcts in adult squirrel monkeys. J. Neurophysiol. 75, 2144-2149.

Nudo, R. J., Milliken, G. W., Jenkins, W. M., and Merzenich, M. M. (1996a). Usedependent alterations of movement representations in primary motor cortex of adult squirrel monkeys. J. Neurosci. 16, 785-807.

Nudo, R. J., Wise, B. M., Sifuentes, F., and Milliken, G. W. (1996b). Neural substrates for the effects of rehabilitative training on motor recovery after ischemic infarct. Science 272, 1791-1794. doi: 10.1126/science.272.5269.1791

Page, S. J. (2003). Intensity versus task-specificity after stroke: how important is intensity? Am. J. Phys. Med. Rehabil. 82, 730-732. doi: 10.1097/01.phm. 0000078226.36000.a5

Pascual-Leone, A., Valls-Solé, J., Wassermann, E. M., and Hallett, M. (1994). Responses to rapid-rate transcranial magnetic stimulation of the human motor cortex. Brain 117, 847-858. doi: 10.1093/brain/117.4.847

Pennisi, G., Rapisarda, G., Bella, R., Calabrese, V., Maertens De Noordhout, A., and Delwaide, P. J. (1999). Absence of response to early transcranial magnetic stimulation in ischemic stroke patients: prognostic value for hand motor recovery. Stroke 30, 2666-2670. doi: 10.1161/01.str.30.12.2666

Platz, T., and Rothwell, J. C. (2010). Brain stimulation and brain repair-rTMS: from animal experiment to clinical trials-what do we know? Restor. Neurol. Neurosci. 28, 387-398. doi: 10.3233/RNN-2010-0570

Reinkensmeyer, D. J., and Boninger, M. L. (2012). Technologies and combination therapies for enhancing movement training for people with a disability. $J$. Neuroeng. Rehabil. 9, 17. doi: 10.1186/1743-0003-9-17

Richards, L. G., Stewart, K. C., Woodbury, M. L., Senesac, C., and Cauraugh, J. H. (2008). Movement-dependent stroke recovery: A systematic review and meta-analysis of TMS and fMRI evidence. Neuropsychologia 46, 3-11. doi: 10. 1016/j.neuropsychologia.2007.08.013

Rossini, P. M., and Pauri, F. (2000). Neuromagnetic integrated methods tracking human brain mechanisms of sensorimotor areas 'plastic' reorganisation. Brain Res. Rev. 33, 131-154. doi: 10.1016/s0169-328x(00) 00090-5

Sandrini, M., and Cohen, L. G. (2013). "Noninvasive brain stimulation in neurorehabilitation," in Handbook of Clinical Neurology, Brain Stimulation, eds A. M. Lozano and M. Hallett. (Amsterdam: Elsevier B.V.), 499-524. doi: 10. 1016/b978-0-444-53497-2.00040-1

Small, S. L., Hlustik, P., Noll, D. C., Genovese, C., and Solodkin, A. (2002). Cerebellar hemispheric activation ipsilateral to the paretic hand correlates with functional recovery after stroke. Brain 125, 1544-1557. doi: 10 1093/brain/awf148

Stagg, C. J., and Nitsche, M. A. (2011). Physiological basis of transcranial direct current stimulation. Neuroscientist 17, 37-53. doi: 10.1177/10738584103 86614

Stefan, K., Kunesch, E., Benecke, R., Cohen, L. G., and Classen, J. (2002). Mechanisms of enhancement of human motor cortex excitability induced by interventional paired associative stimulation. J. Physiol. Lond. 543, 699-708. doi: 10.1113/jphysiol.2002.023317

Stefan, K., Kunesch, E., Cohen, L. G., Benecke, R., and Classen, J. (2000). Induction of plasticity in the human motor cortex by paired associative stimulation. Brain 123, 572-584. doi: 10.1093/brain/123.3.572

Takeuchi, N., Chuma, T., Matsuo, Y., Watanabe, I., and Ikoma, K. (2005). Repetitive transcranial magnetic stimulation of contralesional primary motor cortex improves hand function after stroke. Stroke 36, 2681-2686. doi: 10. 1161/01.str.0000189658.51972.34

Takeuchi, N., Tada, T., Toshima, M., Chuma, T., Matsuo, Y., and Ikoma, K. (2008). Inhibition of the unaffected motor cortex by $1 \mathrm{~Hz}$ repetitive transcranical magnetic stimulation enhances motor performance and training effect of the paretic hand in patients with chronic stroke. J. Rehabil. Med. 40, 298-303. doi: 10.2340/16501977-0181

Talelli, P., Wallace, A., Dileone, M., Hoad, D., Cheeran, B., Oliver, R., et al. (2012). Theta burst stimulation in the rehabilitation of the upper limb: a semirandomized, placebo-controlled trial in chronic stroke patients. Neurorehabil. Neural Repair 26, 976-987. doi: 10.1177/15459683124 37940

Teasell, R., Bitensky, J., Foley, N., and Bayona, N. A. (2005). Training and stimulation in post stroke recovery brain reorganization. Top Stroke Rehabil. 12, 37-45. doi: 10.1310/e893-m0pr-njej-1gxm

Thabit, M. N., Ueki, Y., Koganemaru, S., Fawi, G., Fukuyama, H., and Mima, T. (2010). Movement-related cortical stimulation can induce human motor plasticity. J. Neurosci. 30, 11529-11536. doi: 10.1523/JNEUROSCI.1829-10. 2010

Ueki, Y., Mima, T., Kotb, M. A., Sawada, H., Saiki, H., Ikeda, A., et al. (2006). Altered plasticity of the human motor cortex in Parkinson's disease. Ann. Neurol. 59, 60-71. doi: 10.3410/f.7018.349452

Verheyden, G., Nieuwboer, A., De Wit, L., Thijs, V., Dobbelaere, J., Devos, H., et al. (2008). Time course of trunk, arm, leg and functional recovery after ischemic stroke. Neurorehabil. Neural Repair 22, 173-179. doi: 10. $1177 / 1545968307305456$

Wang, R. Y., Tseng, H. Y., Liao, K. K., Wang, C. J., Lai, K. L., and Yang, Y. R. (2012). rTMS combined with task-oriented training to improve symmetry of interhemispheric corticomotor excitability and gait performance after stroke: a randomized trial. Neurorehabil Neural Repair 26, 222-230. doi: 10. $1177 / 1545968311423265$

Ward, N. S., Brown, M. M., Thompson, A. J., and Frackowiak, R. S. (2003a). Neural correlates of motor recovery after stroke: a longitudinal fMRI study. Brain 126, 2476-2496. doi: 10.1093/brain/awg245

Ward, N. S., Brown, M. M., Thompson, A. J., and Frackowiak, R. S. (2003b). Neural correlates of outcome after stroke: a cross-sectional fMRI study. Brain 126, 1430-1448. doi: 10.1093/brain/awg145

Ward, N. S., Brown, M. M., Thompson, A. J., and Frackowiak, R. S. (2004). The influence of time after stroke on brain activations during a motor task. Ann. Neurol. 55, 829-834. doi: 10.1002/ana.20099

Ward, N. S., and Cohen, L. G. (2004). Mechanisms underlying recovery of motor function after stroke. Arch. Neurol. 61, 1844-1848. doi: 10.1001/archneur.61. 12.1844 
Ward, N. S., Newton, J. M., Swayne, O. B., Lee, L., Thompson, A. J., Greenwood, R. J., et al. (2006). Motor system activation after subcortical stroke depends on corticospinal system integrity. Brain 129, 809-819. doi: 10.1093/brain/awl002

Woldag, H., Stupka, K., and Hummelsheim, H. (2010). Repetitive training of complex hand arm movements with shaping is beneficial for motor improvement in patients after stroke. J. Rehabil. Med. 42, 582-587. doi: 10. 2340/16501977-0558

Zaehle, T., Rach, S., and Herrmann, C.S. (2010). Transcranial alternating current stimulation enhances individual alpha activity in human EEG. PLoS One 5:e13766. doi: 10.1371/journal.pone. 0013766
Conflict of Interest Statement: The authors declare that the research was conducted in the absence of any commercial or financial relationships that could be construed as a potential conflict of interest.

Copyright () 2015 Koganemaru, Fukuyama and Mima. This is an open-access article distributed under the terms of the Creative Commons Attribution License (CC BY). The use, distribution and reproduction in other forums is permitted, provided the original author(s) or licensor are credited and that the original publication in this journal is cited, in accordance with accepted academic practice. No use, distribution or reproduction is permitted which does not comply with these terms. 